Попов В. В. / Хирургическое лечение митрального стеноза, осложненного массивным тромбозом левого...

\title{
Хирургическое лечение митрального стеноза, осложненного массивным тромбозом левого предсердия: госпитальный этап лечения
}

\author{
Попов В. В., Мнишенко В. И., Витовский Р.М. \\ ГУ «Национальный институт сердечно-сосудистой хирургии имени Н. М. Амосова НАМН» (Киев)
}

\begin{abstract}
Изучены особенности хирургического лечения митрального порока, осложненного массивным тромбозом левого предсердия, в условиях искусственного кровообращения. В проанализированную группу были включены 334 пациента, прооперированные в Институте. Предложена классификация пациентов с массивным тромбозом ЛП. Необходимость удаления материнской тромботической выстилки во время операции для профилактики тромбообразования в послеоперационном периоде не вызывает сомнений.

Госпитальная летальность за период с 1999 по 2014 гг. составила 4,8\%. Причинами летальных случаев были острая сердечная недостаточность $(\mathrm{n}=2)$, поражение ЦНС (тромбоэмболия) $(\mathrm{n}=3)$, тромбоэмболия венечной артерии $(\mathrm{n}=1)$, кровотечение $(\mathrm{n}=3)$. К факторам риска на госпитальном этапе отнесены: II-III степень МТЛП, предварительно закрытая митральная комиссуротомия, кальциноз митрального клапана +3 . Хирургическая коррекция МП, осложненного МТЛП, является операцией повышенного риска и сопровождается высокой летальностью.

В группе пациентов было $142(39,8 \%)$ мужчины и $202(60,2 \%)$ женщины. Средний возраст пациентов составил 57,2 $\pm 5,2$ (19-70) года. Все пациенты отнесены к IV классу по NYHA. Этиологической причиной дефекта клапана была ревматическая лихорадка. Средняя постоянная форма фибрилляции предсердий составила $4,1 \pm 0,8$ года.

Во время работы выполнены такие процедуры: замена митрального клапана $(\mathrm{n}=255)$, замена митрального клапана + аннулопластика трехстворчатого клапана Амосова-де Вега $(\mathrm{n}=47)$, изолированная открытая митральная комиссуротомия $(\mathrm{n}=28)$, изолированная открытая митральная комиссуротомия + аннулопластика трехстворчатого клапана Амосова-де Вега $(\mathrm{n}=4)$. Оптимальное отклонение хирургического лечения массивных тромбозов левого предсердия состоит в удалении основы тромботических образований в левом предсердии и перевязывании ушка левого предсердия.
\end{abstract}

Ключевые слова: митральный стеноз, массивный тромбоз левого предсердия, хирургическая коррекция, тромбоэмболические осложнения.

Массивный тромбоз левого предсердия (МТЛП) представляет собой один из сложных разделов хирургии приобретенных пороков митрального клапана сердца $[1,2,4]$. Он составляет $5 \%$ в структуре митрального стеноза (МС) 4-ой степени [6-10]. Несмотря на имеющийся клинический опыт, госпитальная летальность при наличии МТЛП все еще превышает уровень летальности при неосложненной коррекции MC [3-5].

Хирургическое лечение митрального порока в сочетании с МТЛП является операцией высокого риска и сопровождается повышенной госпитальной летальностью, поскольку обусловлено повышенной опасностью тромбоэмболических осложнений (ТО) на госпитальном этапе и в отдаленный период [4-8].

Целью исследования являлось изучение особенностей хирургического лечения МС, осложненного МТЛП, в условиях искусственного кровообращения, с перспективой улучшения непосредственных и отдаленных результатов вмешательства.
Материалы и методы. В анализируемую группу включены 344 пациента с МС, осложненным массивным тромбозом левого предсердия, находившиеся на хирургическом лечении в Национальном институте сердечно-сосудистой хирургии имени Н. М. Амосова НАМН с 01 января 1984 года до 01 января 2015 года. Массивным тромбоз левого предсердия признавался тогда, когда тромботические массы занимали не менее одной трети его объема, не считая его ушка. «Чистый» либо преобладающий митральный стеноз был отмечен во всех случаях. В III классе по Нью-Йоркской классификации (NYHA) находились $95(27,6 \%)$ пациентов, в IV классе - 249 (72,4\%). Пациенты с сопутствующей коррекцией аортального клапана из исследования исключены.

Группу исследования составляли $142(41,3 \%)$ мужчины и $202(58,7 \%)$ женщины. Возраст оперируемых составил 58,8 $\pm 9,1$ (20-71 год) гг. Средняя длительность наличия мерцательной аритмии составила $4,1 \pm 0,8$ года, а ревматического порока - 19,1 44,3 года. Постоян- 
ная форма фибрилляции предсердий отмечена в 97,8\% (327 пациентов) случаев, пароксизмальная форма - в 2,2\% (17 пациентов). На момент операции синусовый ритм фиксировался в $2(0,6 \%)$ случаях. Ревматический генез поражения, в том числе в сочетании с липоидозом, дисплазией, миксоматозной дегенерацией, отмечен в $100,0 \%$ случаев.

Степень распространения МТЛП была неоднородной - от $33 \%$ объема ЛП до субтотальной, что, соответственно, предопределяло и неоднородность клинического течения. Это заставило нас классифицировать пациентов по 3 степеням МТЛП в зависимости от соотношения объема тромботических масс и размера ЛП: І степень - 33 (9,6\%) пациента (объем тромботических масс в пределах $33 \%$ объема ЛП); ІІ степень - 102 (29,7\%) пациента (объем тромботических масс в пределах 34-50\% объема ЛП); ІІІ степень - 209 $(60,8 \%)$ пациентов (объем тромботических масс в пределах $51 \%$ и более от объема ЛП).

Отличительной особенностью МТЛП, кроме объема отложения тромботических масс, является наличие плотного сращения между основанием тромботической выстилки («материнская основа») и эндокардом ЛП. Это в первую очередь касается II и III степени МТЛП: отложения тромботических масс имели плотное сращение со стенкой ЛП (материнская основа-выстилка), включая и зону ушка ЛП. В то же время при I степени МТЛП (33 случая) в 3 случаях зона ушка ЛП не была вовлечена в зону формирования тромба $(0,6 \%$ в структуре всех случаев МТЛП), а в 4 ( $0,8 \%$ в структуре всех случаев МТЛП) случаях в этой группе отсутствовала тромботическая выстилка.

Предложенная классификация позволила нам лучше оценить степень тяжести оперируемых, определить объем оперативного вмешательства и прогноз на послеоперационный период. Распределение ряда клини-

\section{Таблица 1}

Распределение ряда показателей у пациентов при разных степенях МТЛП

\begin{tabular}{llllll} 
Показатели & $\begin{array}{l}\text { I сте- } \\
\text { пень } \\
\text { МТЛП }\end{array}$ & $\begin{array}{l}\text { II сте- } \\
\text { пень } \\
\text { МТлП }\end{array}$ & $\begin{array}{l}\text { III сте- } \\
\text { пень } \\
\text { МТлП }\end{array}$ & P \\
\hline Количество & 33 & 102 & 209 & \\
\hline Длительность MC (г) & $13,4 \pm 3,7$ & $17,8 \pm 3,1$ & $21,5 \pm 4,3$ & $<0,05$ \\
\hline $\begin{array}{l}\text { Фибрилляция } \\
\text { предсердий (г) }\end{array}$ & $2,1 \pm 0,6$ & $3,5 \pm 0,8$ & $5,2 \pm 0,6$ & $<0,05$ \\
\hline М/Ж (\%) & $15 / 18$ & $46 / 56$ & $81 / 128$ & $<0,05$ \\
\hline Возраст (г) & $43,2 \pm 5,7$ & $53,4 \pm 6,1$ & $61,1 \pm 0,7$ & $<0,05$ \\
\hline NYHА IV (\%) & 45,4 & 63,7 & 92,8 & $<0,05$ \\
\hline Д /о ТО (\%) & 18,2 & 21,6 & 24,4 & $<0,05$ \\
\hline $\begin{array}{l}\text { Предшествующие } \\
\text { операции (\%) }\end{array}$ & $6,1(2)$ & $26,5(27)$ & $34,9(73)$ & $<0,05$
\end{tabular}

ческих показателей в зависимости от степени МТЛП представлено в табл. 1.

Согласно данным табл. 1, группа показателей пациентов с I степенью МТЛП существенно отличалась от данных пациентов в группах II и III степени МТЛП $(\mathrm{p}<0,05)$. Это в полной мере соответствовало морфологическому субстрату патологии. Фактически показатели у пациентов при III степени МТЛП были клинически самыми тяжелыми, свидетельствующими о крайней степени риска вмешательства при длительном наличии ревматического порока и фибрилляции предсердий.

Тромбоэмболия сосудов большого крута кровообращения выявлена в анамнезе у 79 пациентов $(22,9 \%)$, у $15(4,4 \%)$ из них она отмечена неоднократно. Это является патогномоничным критерием для данной категории пациентов (каждый пятый). У всех отмечена постоянная форма фибрилляции предсердий со средней длительностью $3,5 \pm 0,5$ года и длительностью наличия ревматического порока $21,1 \pm 4,5$ года. Тромбоэмболические осложнения отмечались перед операцией в сроки $2,1 \pm 0,3$ года, и, что важно, в $13(3,8 \%)$ случаях не были отмечены пациентами, а выявлены лишь при вскрытии (постинсультные кисты мозга, почек, селезенки). Это происходило на этапах формирования МТЛП, когда имел место отсев мелких тромбов, протекавший незамечено для пациента и клинически не манифестировавший. Однако предоперационные тромбоэмболические осложнения (явные или скрытые) влияли на клиническое течение, поэтому у всех пациентов с МТЛП целесообразно выполнять скрининговое КТ всего организма до операции.

В большинстве случаев дооперационных ТО доминировала тромбоэмболия в сосуды головного мозга (ТЭСГМ) - у 71 (89,8\% больных с тромбоэмболиями), включая трех пациентов с тромбоэмболией сосудов сетчатки глаза. Из них к моменту поступления в стационар 19 (28,4\% всех ТЭСГМ) больных имели остаточные явления нарушения мозгового кровообращения в виде гемипареза.

Дооперационные ТО отмечены: при степени 1 МТЛП - в 18,2\% (n=6/33) случаев, при степени 2 МТЛП - в 21,6\% (n=22/102), при степени 3 МТЛП - в $24,4 \%(\mathrm{n}=51 / 209)(\mathrm{p}<0,05)$. Таким образом, наблюдалась прямо пропорциональная зависимость частоты дооперационной ТО в зависимости от выраженности МТЛП.

У всех пациентов отмечалась повышенная склонность к тромбообразованию, которая, помимо ФП, также была обусловлена следующими показателями крови: гемоглобин - $159,1 \pm 14,5$ г/л, гематокрит -

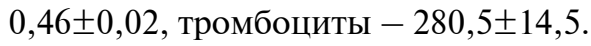

Ранее операция на митральном клапане была выполнена 104 больным $(30,2 \%)$, в основном по закрытой методике. Из них у 97 (93,3\%\% в структуре повторных операций) была произведена закрытая митральная комиссуротомия, у 4 (3,8\%) - закрытая 
рекомиссуротомия, у 3 (2,9\%) пациентов - открытая митральная комиссуротомия.

Кальциноз диагностирован у $227(66,0 \%)$ из 344 оперированных пациентов, в том числе: кальциноз I степени выявлен у $33(9,6 \%)$ пациентов, II степени у 96 (27,9\%), III степени - у 98 (28,5\%). Выраженные фиброзные изменения на Мк выявлены у 117 (34,0\%) больных, что лимитировало выполнение клапаносберегающих операций.

За 30-летний период методики обеспечения операций существенно изменились, поэтому будет приведено описание разработок последних десятилетий. Операции выполнены в условиях ИК, умеренной гипотермии $\left(27-32{ }^{\circ} \mathrm{C}\right)$, в условиях кристаллоидной кардиоплегии (преимущественно Кустодиол). Время

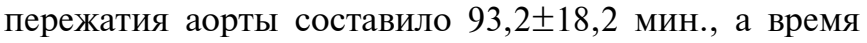

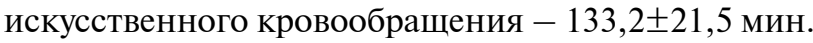

Протезирование митрального клапана ввиду выраженной его деформации (кальциноз, грубый фиброз) было выполнено в большинстве случаев - 301 (87,5\%), а реконструкция клапана (открытая митральная комиссуротомия - ОМК) - лишь в $43(12,5 \%)$ случаях.

Корригировался сопутствующий трикуспидальный порок $(\mathrm{n}=68,19,7 \%)$. По характеру коррекции пораженного Тк все оперируемые пациенты разделены на 2 группы: 1) ПМК + аннулопластика Тк по Н. М. Амосову (при его функциональной недостаточности) - 57 (83,8\% в структуре всех ТП); ОМК + аннулопластика Тк (АТК) по Н. М. Амосову (при его функциональной недостаточности) - $3(4,4 \%)$; 2) ПМК, комиссуротомия и аннулопластика Тк по Н. М. Амосову (при его органическом поражении) - 7 (10,3\%) пациентов; ОМК, комиссуротомия и аннулопластика Тк по Н М. Амосову (при его органическом поражении) - 1 (1,5\%) пациент.

Был имплантирован 301 митральный протез следующих типов: МКЧ-25 - 12 (4,0\%), МКЧ-27 $13(4,3 \%)$, биопротезы - 3 (1,0\%), монодисковые (ЭМИКС, ЛИКС, МИКС, АЛЬКАРБОН, ЭЛМАК) 83 (27,6\%), двустворчатые (Saint Jude, ON-X, EdwardsMIRA, Carbomedics) - 190 (63,1\% пациентов). В связи с постоянной формой фибрилляции предсердий в 15 $(4,4 \%)$ случаях применена методика Лабиринт. При наличии дилатации левого предсердия (более 60 мм показатель атриомегалии) выполнялась пластика задней стенки ЛП у $25(7,3 \%)$ пациентов, в том числе у 20 $(5,8 \%)$ пациентов по методике Кавазое и у $5(1,5 \%)$ по оригинальной методике треугольной пластики ЛП.

Сопутствующая ишемическая болезнь сердца отмечена у $39(11,3 \%)$ пациентов (средний возраст $57,1 \pm 4,7$ лет), у $9(2,6 \%)$ из них выполнено венозное аортокоронарное шунтирование: шунтирование 1 коронарной артерии (6 пациентов), 2 коронарных артерий (3 пациента). Гипертоническая болезнь 1-2 степени отмечена у 57 (16,5\%).

В случае умеренного фиброза Мк и единичных небольших вкраплений кальция выполнялась рекон- струкция в виде открытой митральной комиссуротомии у 43 (12,5\%) пациентов; у 4 (9,3\%) из них реконструкция дополнена комиссуропластикой по Риду.

В оптимальном варианте при наличии массивного тромбоза левого предсердия тромботические массы удалялись вместе с его основанием-выстилкой [1-9]. Этой процедуре мы придаем принципиальное значение, поскольку остающаяся на стенке левого предсердия шероховатость приводит в раннем послеоперационном периоде, а затем и в отдаленном периоде к рецидивам отложения тромботических масс на шероховатой поверхности основания-выстилки и в дальнейшем к тромбоэмболическим осложнениям.

При проведении всех операций старались полностью удалить все тромботические массы, в том числе и основание тромба, часто представляющее собой хорошо организованную соединительную ткань, плотно фиксированную к стенке предсердия. Отделение основания происходило вместе с подлежащими тканями, и остающаяся поверхность предсердия выглядела слегка неровной, шероховатой. Оставались нити фибрина, которые приходилось дополнительно удалять тупфером. Пространство между стенкой предсердия и тромбом постепенно расширяли, достигая устьев остальных легочных вен и фиброзного кольца митрального клапана. Как правило, кальцификация внутренних слоев тромба (7 случаев) не препятствовала мобилизации тромба. Но значительные трудности встречались при отделении тромба от кальцинированной стенки предсердия.

Радикальным вариантом устранения тромботических масс считается их удаление вместе с основанием-выстилкой, а частичным - удаление лишь тромботическимх масс с оставлением материнской основы. При ПМК радикальный вариант был применен у $138(45,8 \%, n=138 / 301)$, а частичный - у 163 ( 54,2\%, n=163/301) пациентов. При ОМК радикальный вариант был применен у $23(53,5 \%, \mathrm{n}=23 / 43)$ оперированных, а частичный - у $20(46,5 \%, n=20 / 43)$. После удаления всех тромботических масс полость ЛП промывали 0,5 литрами физиологического раствора, закрыв при этом левое атриовентрикулярное отверстие марлевой салфеткой. Затем проводилась тщательная визуальная инспекция ЛП, а после разделения створок Мк или после иссечения - еще и полости ЛЖ.

Зависимость радикального удаления МТЛП от степени его выраженности представлена в табл. 2.

Согласно табл. 2, удельный вес радикального удаления МТЛП находится в обратно пропорциональной зависимости от степени его выраженности.

При радикальном варианте устранения тромботических масс существует угроза разрыва стенки ЛП, отмеченная у $7(2,0 \%, \mathrm{n}=7 / 344)$ пациентов. Все случаи разрыва имели место у пациентов при III степени МТЛП $-3,3 \%(n=7 / 209)$. Ни в одном случае это не явилось причиной смерти. В 6 случаях выполнялось 


\section{Таблица 2}

Распределение радикального удаления МТЛП от

степени выраженности МТЛП

\begin{tabular}{lccc} 
Степень МТлП & $\begin{array}{c}\text { Радикальное } \\
\text { удаление }\end{array}$ & $\begin{array}{c}\text { Удельный } \\
\text { вес (\%) }\end{array}$ & $\mathbf{P}$ \\
\hline I (n=33) & 26 & 78,7 & $<0,05$ \\
\hline II (n=102) & 49 & 48,8 & $<0,05$ \\
\hline III (n=209) & 70 & 33,5 & $<0,05$ \\
\hline ИТОГО & 145 & 42,2 &
\end{tabular}

ПМК, в 1 - ОМК. В 3 случаях применялась аутоперикардиальная вставка в зоне разрыва, а в остальных 4 обычное ушивание.

Вторым важным элементом радикального устранения источника ТЭ-осложнения и в целом радикальности устранения тромбоэмболических угроз являются манипуляции на ушке ЛП: для пациентов с МТЛП (у которых склонность к тромбообразованию считается самым важным элементом патологии) лигирование ушка (ушиванием изнутри либо перевязывнием снаружи) является непременным и обязательным компонентом при хирургическом лечении МТЛП $[1,5,8$, 9]. У 161 (46,8\%) пациента оно было лигировано. При этом ушивание ушка изнутри выполнено у 107 (66,5\% в структуре лигированных ушек) пациентов, перевязывание снаружи - у 44 (33,5\%). У 104 пациентов уже было лигировано ушко ЛП при предшествующем вмешательстве на Мк - закрытой митральной комиссуротомии. Таким образом ушко ЛП оказалось лигированным у $256(74,4 \%)$ пациентов.

Однако при учете сочетания выстилка/ушко (два ключевых фактора при тромбообразовании) оказалось, что наблюдались следующие варианты коррекции устранения тромботических масс и дальнейшей профилактики отложения: вариант 1: радикальное удаление тромботической выстилки + лигирование ушка ЛП - 43,4\% (n=145/344); вариант 2: радикальное удаление тромботической выстилки + ушко ЛП интактно $-4,8 \%(n=16 / 344)$; вариант 3 : частичное удаление тромботической выстилки + лигирование ушка ЛП - 33,2\% (n=111/344); вариант 4: частичное удаление тромботической выстилки + ушко ЛП интактно $21,6 \%(n=72 / 344)$.

Распределение вариантов удаление выстилки/лигирование ушка ЛП по степеням МТЛП представлено в табл. 3.

Согласно табл. 3, радикальный вариант коррекции 1 был применен: при І степени МТЛП - в 78,8\% случаев, при II степени МТЛП - в 48,0\% случаях, при III степени МТЛП - в 33,4\% случаях $(\mathrm{p}<0,05)$, что свидетельствует о том, что возможность выполнения радикального устранения МТЛП снижается при возрастании степени отложения массивного тромбоза в
ЛП. Аналогичная закономерность отмечена при всех остальных 3 вариантах.

Результаты и их обсуждение. Госпитальная летальность за период 2000-2014 гг. составила 4,2\% при ПМК и 0,0\% при ОМК. За этот период причинами летальных исходов при ПМК явились острая сердечно-сосудистая недостаточность $(\mathrm{n}=4)$, поражение центральной нервной системы (тромбоэмболия) $(\mathrm{n}=3)$, кровотечение $(\mathrm{n}=4)$, полиорганная недостаточность $(\mathrm{n}=1)$. Госпитальная летальность зависела от степени МТЛП: І степень- 0\%, II степень - 3,9\%, III степень $5,1 \%(\mathrm{p}<0,05)$.

Отмечена прямо пропорциональная зависимость госпитальной летальности по причине летальных тромбоэмболических осложнений (все) в зависимости от степени МТЛП за весь период исследования: при I степени МТЛП - 0,0\% ( $\mathrm{n}=0 / 22)$, при II степени МТЛП - 3,5\% (n=3/86), при III степени МТЛП - 5,2\% $(\mathrm{n}=10 / 193)(\mathrm{p}<0,05)$.

Распределение вариантов профилактики ТЭО (удаление выстилки/лигирование ушка ЛП) по степени МТЛП при ПМК для всех случаев ТО (суммарно) представлено в табл. 4.

Как следует из представленных данных табл. 4, лишь полное выполнение всех мероприятий по устранению тромботических масс (выстилка-основание), а также источника возможных ТО (ушко) (группа 1) позволяет получить статистически низкую величину госпитальной летальности по причине ТО в вариан-

\section{Таблица 3}

Распределение вариантов удаление выстилки/ лигирование ушка ЛП по степеням МТЛП

\begin{tabular}{|c|c|c|c|c|}
\hline & $\begin{array}{c}\text { Вариант 1: } \\
\text { ради- } \\
\text { кальное } \\
\text { удаление } \\
\text { выстил- } \\
\text { ки + лиги- } \\
\text { рование } \\
\text { ушка лп }\end{array}$ & $\begin{array}{c}\text { Вариант 2: } \\
\text { ради- } \\
\text { кальное } \\
\text { удаление } \\
\text { выстил- } \\
\text { ки + ушка } \\
\text { ЛП интак- } \\
\text { тно }\end{array}$ & $\begin{array}{c}\text { Вариант 3: } \\
\text { частичное } \\
\text { удаление } \\
\text { тромбо- } \\
\text { тической } \\
\text { выстилки + } \\
\text { лигирова- } \\
\text { ние ушка }\end{array}$ & $\begin{array}{c}\text { Вариант 4: } \\
\text { частичное } \\
\text { удаление } \\
\text { тромбо- } \\
\text { тической } \\
\text { выстилки + } \\
\text { ушко Лп } \\
\text { интактно }\end{array}$ \\
\hline $\begin{array}{l}\text { І степень } \\
\text { МТЛП (n=33) }\end{array}$ & 26 & 1 & 5 & 1 \\
\hline $\begin{array}{l}\text { Удельный } \\
\text { вес (100,0\%) }\end{array}$ & 78,8 & 3,0 & 15,2 & 3,0 \\
\hline $\begin{array}{l}\text { II степень } \\
\text { МТЛП } \\
(\mathrm{n}=102)\end{array}$ & 49 & 1 & 28 & 24 \\
\hline $\begin{array}{l}\text { Удельный } \\
\text { вес (100,0\%) }\end{array}$ & 48,0 & 1,0 & 27,5 & 23,5 \\
\hline $\begin{array}{l}\text { III степень } \\
\text { МТЛП } \\
(\mathrm{n}=209)\end{array}$ & 70 & 14 & 78 & 47 \\
\hline $\begin{array}{l}\text { Удельный } \\
\text { вес (100,0\%) }\end{array}$ & 33,4 & 6,7 & 37,3 & 22,6 \\
\hline Всего & 145 & 16 & 111 & 72 \\
\hline
\end{tabular}




\section{Таблица 4}

Удельный вес летальных ТЭО (всех) в зависимости от методов профилактики ТЭО (удаление выстилки) лигирование ушка ЛП) по степени МТЛП при ПМК

\begin{tabular}{|c|c|c|c|c|}
\hline & $\begin{array}{c}\text { Вариант 1: } \\
\text { ради- } \\
\text { кальное } \\
\text { удаление } \\
\text { выстилки + } \\
\text { лигирова- } \\
\text { ние ушка } \\
\text { лп }\end{array}$ & $\begin{array}{c}\text { Вариант 2: } \\
\text { ради- } \\
\text { кальное } \\
\text { удаление } \\
\text { выстилки + } \\
\text { ушка ЛП } \\
\text { интактно }\end{array}$ & $\begin{array}{c}\text { Вариант 3: } \\
\text { частичное } \\
\text { удаление } \\
\text { тромбо- } \\
\text { тической } \\
\text { выстилки + } \\
\text { лигирова- } \\
\text { ние ушка }\end{array}$ & $\begin{array}{c}\text { Вариант 4; } \\
\text { частичное } \\
\text { удаление } \\
\text { тромбо- } \\
\text { тической } \\
\text { выстилки + } \\
\text { ушко ЛП } \\
\text { интактно }\end{array}$ \\
\hline $\begin{array}{l}\text { I степень } \\
\text { МТЛП (n=22) }\end{array}$ & $18 / 0$ & $0 / 0$ & $3 / 0$ & $1 / 0$ \\
\hline $\begin{array}{l}\text { Частота ТО } \\
\text { (\%) }\end{array}$ & 0,0 & 0,0 & 0,0 & 0,0 \\
\hline $\begin{array}{l}\text { II степень } \\
\text { МТЛП }(n=86)\end{array}$ & $42 / 1$ & $1 / 1$ & $23 / 0$ & $20 / 1$ \\
\hline $\begin{array}{l}\text { Частота ТО } \\
\text { (\%) }\end{array}$ & 2,4 & 100,0 & 0,0 & 5,0 \\
\hline $\begin{array}{l}\text { III степень } \\
\text { МТЛП } \\
(n=193)\end{array}$ & $64 / 1$ & $13 / 0$ & $74 / 7$ & $42 / 2$ \\
\hline $\begin{array}{l}\text { Частота ТО } \\
\text { (\%) }\end{array}$ & 1,6 & 0,0 & 9,5 & 4,7 \\
\hline итого & $124 / 2$ & $14 / 1$ & $100 / 7$ & $63 / 3$ \\
\hline Частота (\%) & 1,6 & 7,1 & 7,0 & $4,8 \%$ \\
\hline
\end{tabular}

(n|n) - количество прооперированных / в том числе умерших

те 1. Следует отметить очень низкий уровень ТО при III степени МТЛП в вариантах 1 и 2 (полное удаление основания выстилки): $1,6 \%(\mathrm{n}=1 / 64)$ и $0 \%(\mathrm{n}=0 / 13)$ $(\mathrm{p}<0,05)$. При ОМК лишь при варианте 3 (невзирая на лигирование ушка) отмечена госпитальная летальность $18,2 \%(\mathrm{n}=2 / 11)(\mathrm{p}<0,05)$ по причине ТО, что свидетельствует о целесообразности удаления тромботической материнской основы.

Госпитальная летальность зависела от наличия предшествующей закрытой митральной комиссуротомии (3МК): 5,7\% летальности в группе после 3МК и $2,5 \%$ без нее $(\mathrm{p}<0,05)$. Госпитальная летальность зависела от наличия кальциноза +3 на митральном клапане и составила $8,2 \%$ в группе с кальцификацией Мк +3 и $2,1 \%$ в группе с отсутствием кальциноза $+3(\mathrm{p}<0,05)$. Донорская кровь и ее компоненты не использовались за весь госпитальный период у $27(7,8 \%)$ пациентов [8]. Правильный ритм при выписке отмечен лишь у 15 (4,5\%) пациентов, 12 из которых - после операции Лабиринт [11]. Кроме непрямых антикоагулянтов пациентам назначались антиагреганты с 5-го дня [10].

Выводы. При выполнении хирургической коррекции у пациентов с МТЛП важным элементом операции является удаление основания-выстилки и перевязывание ушка левого предсердия, что существенно снижает риск госпитальной летальнос- ти, тромбоэмболических осложнений на госпитальном этапе. Предложенный вариант классификации МТЛП позволяет четко выявить степень тяжести оперированных пациентов и вероятность развития ТО-осложнений. Проведение скринингового компьютерного томографического исследования головы и органов брюшной полости является обязательным для исключения «немых» эпизодов тромбоэмболий до операции. Операция Лабиринт является желательным элементом операции. Строгая антиагрегантная терапия является важным элементом профилактики ТО.

\section{Литература}

1. Mitral valve stenosis associated with a floating ball thrombus in the left atrium; report of a case / Doiguchi M., Ikei S., Mizutani M. et al. //. Kyobu Geka. - 2002, Jul. Vol. 55(7). - P. 585-7.

2. Paroxysmal postural dyspnea related to a left atrial ball thrombus / Grandmougin D., Letourneau T., Favre J. P. et al. // Ann Thorac Surg. - 2002. - Vol. 74. - P. 1691-1694.

3. Left atrial ball-shaped thrombus mimicking myxoma detected by transthoracic echocardiography / Tьmbklı M. M., Naseri E., Ceyhan K. et al. // Anadolu Kardiyol Derg. - 2007. - Vol. 7 (3). - P. 355.

4. Giant left atrial ball thrombus in a patient with chronic nonvalvular atrial fibrillation / Lee J. H., Kang S. K., Lee C. W. et al. // Ann Thorac Surg. - 2008 Jan. - Vol. 85 (1). - P. 313-5.

5. Left atrial thrombus without mitral disease; report of a case / Murayama J., Itoh T., Natsuaki M. et al. // Kyobu Geka. - 2003. - Vol. 56 (13). - P. 1130-3.

6. Лечение митрального стеноза, осложненного массивным тромбозом левого предсердия / Попов В. В., Кнышов Г. В., Мнишенко В. И. // Таврический медико-биологический вестник. - 2013. - Том 16, № 3. - C. 123-125.

7. Хирургическое лечение митрального стеноза, осложненного массивным тромбозом левого предсердия / Кнышов Г. В., Попов В. В., Мнишенко В. И., Попова Е. В. // Український кардіологічний журнал. - 2012, Додаток 1. - 2012. - С. 162.

8. Greater volume of acute normovolemic hemodilution may aid in reducing blood transfusions after cardiac surgery/ Goldberg J., Paugh T., Dickinson T. et al. // Annals of Thoracic Surgery. - 2015. - Vol. 100, N 5. - P. 1581-1587

9. Saint Jude mechanical valve for isolated mitral valve disease complicated massive thromboses of left atrium / Pukas K. V., Popov V. V., Lazorishinetz V. V. et al. // Controversies and Advancement in the Treatment of Cardiovascular Disease The Fifteenthin the Seriesi - November 19\&20, 2015, Montage Beverly Hillsю - P. 11.

10. Postoperative atrial fibrillation in associated with high on-aspirin platelet reactivity / Kopjar T., Petricevic M., Gasparovich H. et al. // Annals of Thoracic Surgery. 2015. - Vol. 100, N 5. - P. 1704-1711.

11. Mitral valve surgery: 1257 consecutive procedures / Murphy D., Moss E., Binongo J. et al. // Annals of Thoracic Surgery. - 2015. - Vol. 100, N 5. - P. 1675-1682. 


\title{
Surgical treatment of mitral valve diseases in combination with massive thrombosis of left atrium: treatment at hospital period
}

\author{
Popov V. V., Mnischenko V. I., Vitovskyi R.M.
}

National M. M. Amosov Institute of Cardiovascular Surgery National Academy of Medical Sciences of Ukraine (Kyiv)

Peculiarities of surgical treatment of mitral valve disease complicated with massive thrombosis of left atrium with cardiopulmonary bypass was examined. Analyzed group consists of 334 patients operated from $1984 \mathrm{y}$. till $2014 \mathrm{y}$. Massive thromboses of left atrium was definited in patients with volume of thrombotic masses was more than $1 / 3$ of hole volume of left atrium not caunted volume of auriculum. Mitral stenoses clear or predominated was marked in all cases.

There were $142(39,8 \%)$ males and $202(60,2 \%)$ females. Average age of patients was 57,2 $\pm 5,2(19-70)$ yy. All patients belong to IY NYHA class. Etiological cause of valve defect was rheumatic fever. Average being of permanent form of atrial fibrillation was $4,1 \pm 0,8$ yy.

The following procedures were performed during operation: isolated mitral valve replacement $(n=255)$, isolated mitral valve replacement + annuloplasty tricuspid valve by Amosov-de Vega $(n=47)$, isolated open mitral commisurothomy $(n=28)$, isolated open mitral commisurothomy + annuloplasty tricuspid valve by Amosov-de Vega $(n=4)$. The optimum variance of surgical treatment of massive thromboses of left atrium is removing removing basement of thrombotic formation at the left atrium and ligation of auriculum of the left atrium.

Hospital mortality during period from 1999 to $2014 \mathrm{y}$. was 4.8\%. Hospital mortality in cases of mitral valve replacement was $6.1 \%$ and in cases of open mitral commisurothomy $-0 \%$. Reasons of fatal outcomes were: acute cardiac and vascular failure $(n=4)$, central nervous system injury (thromboembolism) $(n=3)$, multyorgan failure $(n=3)$, bleeding $(n=4)$.

Specific lethal complications - thrombembolic were marked especially in patients with absence removing of thrombotic basement of the left atrium and ligation of left atrium`s auriculum.

Key words: massive thromboses of left atrium, cardiopulmonary bypass, surgical treatment, mitral valve replacement, open mitral commissurotomy.

\section{Хірургічне лікування мітрального стенозу, ускладненого масивним тромбозом лівого передсердя: госпітальний етап лікування}

\author{
Попов В. В., Мнішенко В. І., Вітовський Р.М. \\ ДУ «Національний інститут серцево-судинної хірургії імені М. М. Амосова НАМН» (Київ)
}

Вивчено особливості хірургічного лікування мітральної вади, ускладненої масивним тромбозом лівого передсердя, в умовах штучного кровообігу. В проаналізовану групу включено 334 пацієнти, прооперовані в Інституті. Запропоновано класифікацію пацієнтів із масивним тромбозом ЛП. Необхідність видалення материнської тромботичного вистилання під час операції для профілактики тромбоутворень у післяопераційному періоді не викликає сумнівів.

Госпітальна летальність за період з 1999 по 2014 рік склала 4,8\%. Причинами летальних випадків були гостра серцева недостатність $(\mathrm{n}=2)$, ураження ЦНС (тромбоемболія) $(\mathrm{n}=3)$, тромбоемболія вінцевої артерії $(\mathrm{n}=1)$, кровотеча $(\mathrm{n}=3)$. До факторів ризику на госпітальному етапі належали: II-III ступінь МТЛП, попередня закрита мітральна комісуротомія, кальциноз мітрального клапана +3. Хірургічна корекція МВ, ускладненої МТЛП, $є$ операцією підвищеного ризику і супроводжується високою летальністю.

У групі пацієнтів було $142(39,8 \%)$ чоловіки і $202(60,2 \%)$ жінки. Середній вік пацієнтів становив $57,2 \pm 5,2$ (19-70) років. Усі пацієнти віднесені до класу IV NYHA. Етіологічною причиною дефекту клапана була ревматична лихоманка. Середня постійна форма фібриляції передсердь склала $4,1 \pm 0,8$ року.

Під час роботи виконано такі процедури: заміна мітрального клапана $(\mathrm{n}=255)$, заміна мітрального клапана + анулопластика тристулкового клапана Амосова-де Вега $(\mathrm{n}=47)$, ізольована відкрита мітральная комісуротомія $(\mathrm{n}=28)$, ізольована відкрита мітральна комісуротомія + анулопластика тристулкового клапана Амосова-де Вега $(\mathrm{n}=4)$. Оптимальне відхилення хірургічного лікування масивних тромбозів лівого передсердя полягає у видаленні основи тромботичних утворень у лівому передсерді та перев’язуванні вушка лівого передсердя.

Ключові слова: масивний тромбоз лівого передсердя, протезування мітрального клапана, відкрита мітральна комісуротомія, штучний кровообіг. 